Prepared in cooperation with Yellowstone National Park, the University of Utah, the University of Wyoming, the Idaho Geological Survey, the Montana Bureau of Mines and Geology, the Wyoming State Geological Survey, and UNAVCO

\title{
Protocols for Geologic Hazards Response by the Yellowstone Volcano Observatory
}

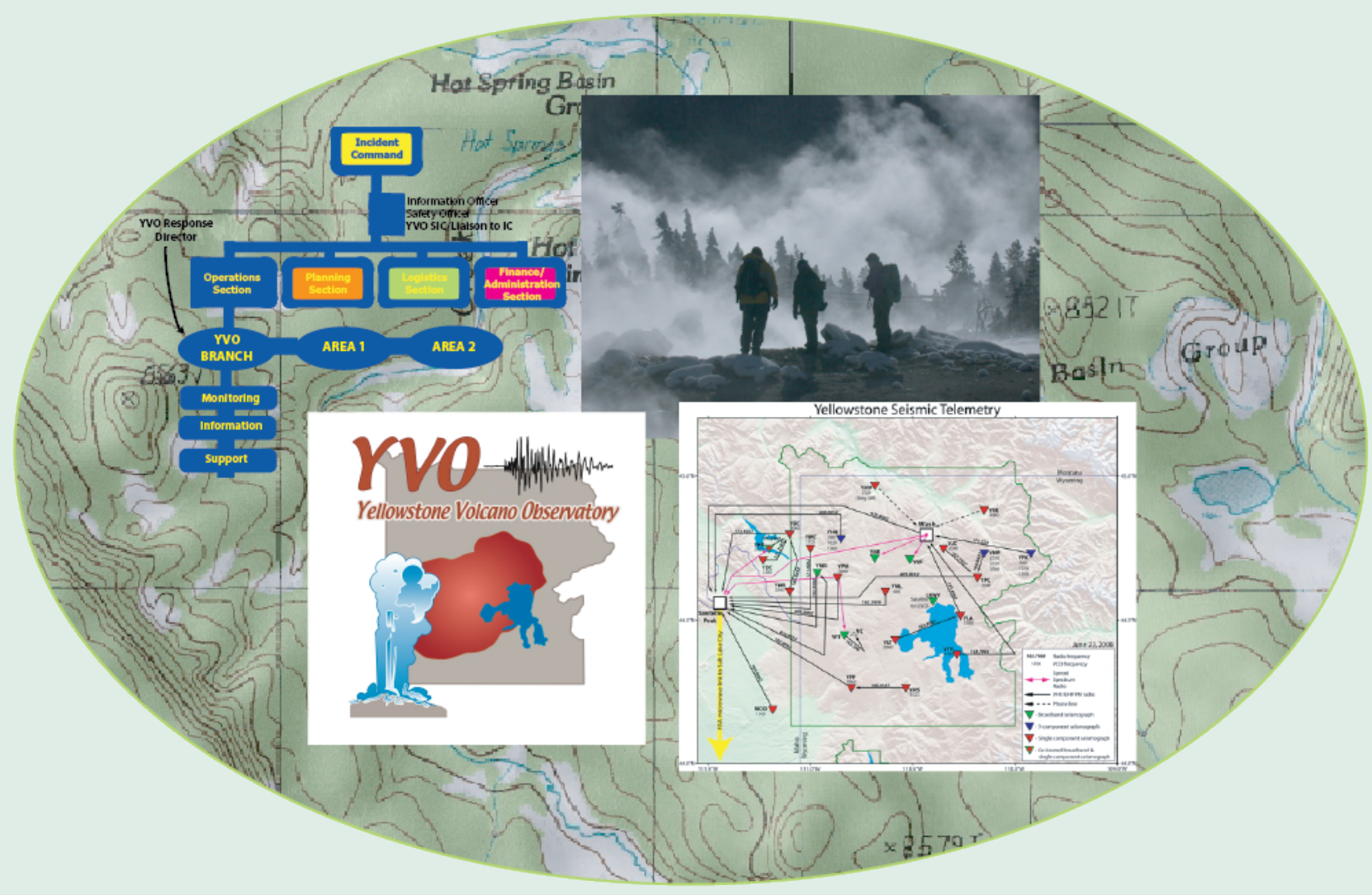

Circular 1351

Version 2.0, November 2014 
Cover: Images clockwise from upper left: Schematic organization of an Incident Command incorporating Yellowstone Volcano Observatory.

University of Utah and Yellowstone National Park staff during wintertime equipment deployment.

Example of data routing for monitoring data from Yellowstone Seismic Network.

Logo of Yellowstone Volcano Observatory. 


\section{Protocols for Geologic Hazards Response by the Yellowstone Volcano Observatory}

By the Yellowstone Volcano Observatory

Circular 1351

Version 2.0, November 2014

U.S. Department of the Interior

U.S. Geological Survey 


\title{
U.S. Department of the Interior SALLY JEWELL, Secretary
}

\author{
U.S. Geological Survey \\ Suzette M. Kimball, Acting Director \\ U.S. Geological Survey, Reston, Virginia \\ First release: 2010 \\ Revised and reprinted: November 2014 (ver. 2.0)
}

\begin{abstract}
For more information on the USGS - the Federal source for science about the Earth, its natural and living resources, natural hazards, and the environment-visit http://www.usgs.gov or call 1-888-ASK-USGS
\end{abstract}

For an overview of USGS information products, including maps, imagery, and publications, visit http://www.usgs.gov/pubprod

To order this and other USGS information products, visit http://store.usgs.gov

Suggested citation:

Yellowstone Volcano Observatory, 2014, Protocols for geologic hazards response by the Yellowstone Volcano Observatory (ver. 2.0, November 2014): U.S. Geological Survey Circular 1351, 16 p., http://dx.doi.org/10.3133/cir1351.

Any use of trade, firm, or product names is for descriptive purposes only and does not imply endorsement by the U.S. Government.

Although this information product, for the most part, is in the public domain, it also may contain copyrighted materials as noted in the text. Permission to reproduce copyrighted items must be secured from the copyright owner.

ISSN: 1067-084X (print)

ISSN: 2330-5703 (online) 


\section{Contents}

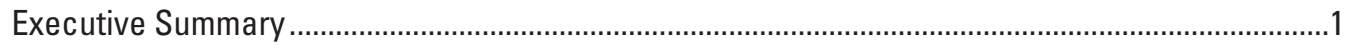

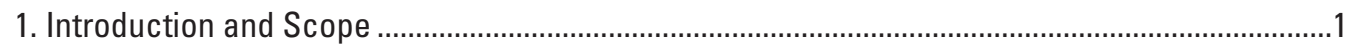

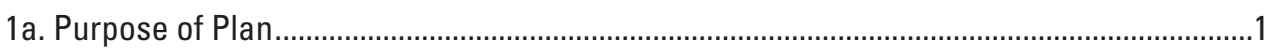

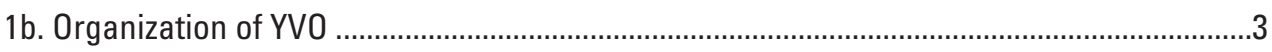

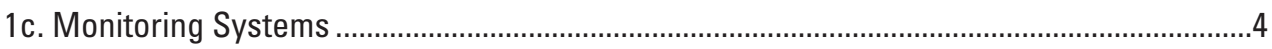

2. Geologic Unrest, Alert Levels, and Information Products .......................................................

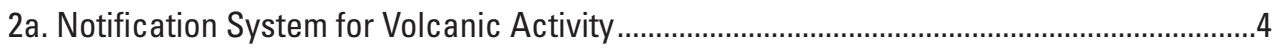

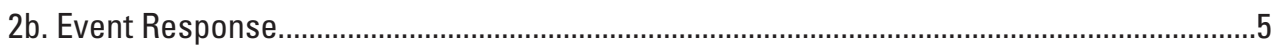

2c. Written Information Products.....................................................................................

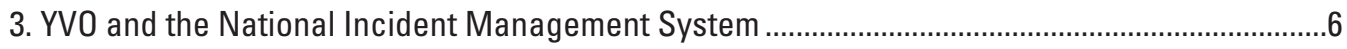

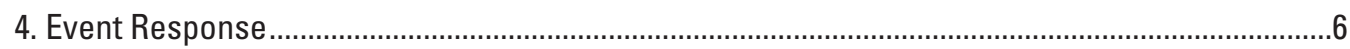

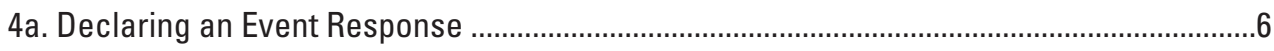

4b. Relation of YVO Event Response to Incident Command System .......................................

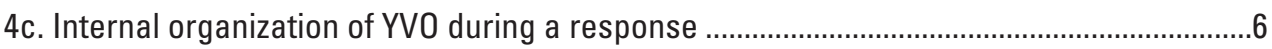

Monitoring Group ...............................................................................................................

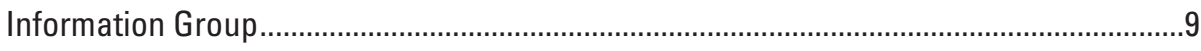

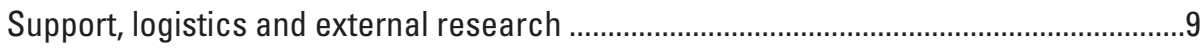

4d. Calldown and Related Communications Lists.................................................................10

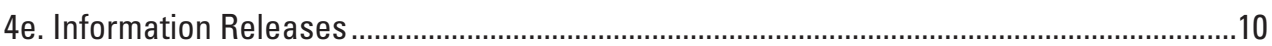

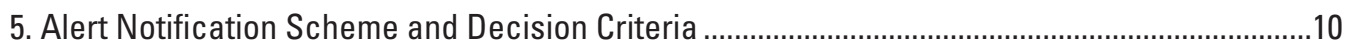

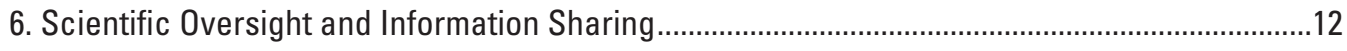

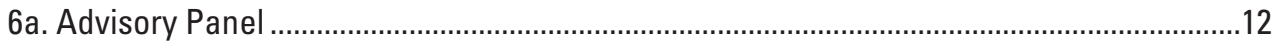

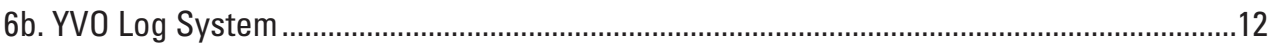

7. Scenarios of Unrest and Initiation of Event Response ...........................................................12

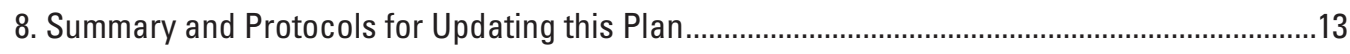

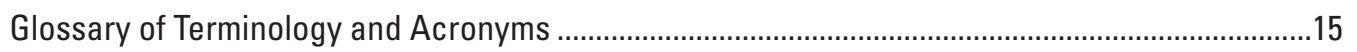

\section{Figures}

1. Location map for Yellowstone National Park.............................................................................

2. Organization chart of Yellowstone Volcano Observatory .........................................................

3. Charts showing the U.S. Geological Survey Volcano Hazards Program system for volcano alert levels..................................................................................................................

4. Hypothetical organization chart of an Incident Command System during an event response at the Yellowstone Caldera ............................................................................................

5. Chart showing Yellowstone Volcano Observatory Branch Organization.....................................8

6. Simplified calldown list for Yellowstone Volcano Observatory ...............................................11 


\section{Conversion Factors}

SI to Inch/Pound

\begin{tabular}{lcl}
\hline & \multicolumn{1}{c}{ Multiply } & \multicolumn{1}{c}{ To obtain } \\
\hline & Length & \\
\hline centimeter $(\mathrm{cm})$ & 0.3937 & inch (in.) \\
meter $(\mathrm{m})$ & 3.281 & foot $(\mathrm{ft})$ \\
kilometer $(\mathrm{km})$ & 0.6214 & mile $(\mathrm{mi})$ \\
\hline \multicolumn{3}{c}{ Area } \\
\hline square meter $\left(\mathrm{m}^{2}\right)$ & 0.0002471 & acre \\
square meter $\left(\mathrm{m}^{2}\right)$ & 10.76 & square foot $\left(\mathrm{ft}^{2}\right)$ \\
\hline & Volume & \\
\hline liter $(\mathrm{L})$ & 0.2642 & gallon $($ gal $)$ \\
\hline & Flow rate & \\
\hline liter per minute $(\mathrm{L} / \mathrm{m})$ & 0.26 & gallon per minute $(\mathrm{gal} / \mathrm{min})$ \\
\hline
\end{tabular}

Temperature in degrees Celsius $\left({ }^{\circ} \mathrm{C}\right)$ may be converted to degrees Fahrenheit $\left({ }^{\circ} \mathrm{F}\right)$ as follows: ${ }^{\circ} \mathrm{F}=\left(1.8 \mathrm{x}^{\circ} \mathrm{C}\right)+32$.

\section{Datum}

Horizontal coordinate information is referenced to the North American Datum of 1983 (NAD 83). 


\title{
Protocols for Geologic Hazards Response by the Yellowstone Volcano Observatory
}

\author{
By the Yellowstone Volcano Observatory ${ }^{1}$
}

\section{Executive Summary}

The Yellowstone Plateau hosts an active volcanic system, with subterranean magma (molten rock), boiling, pressurized waters, and a variety of active faults with significant earthquake hazards. Within the next few decades, light-to-moderate earthquakes and steam explosions are certain to occur. Volcanic eruptions are less likely, but are ultimately inevitable in this active volcanic region. This document summarizes protocols, policies, and tools to be used by the Yellowstone Volcano Observatory (YVO) during earthquakes, hydrothermal explosions, or any geologic activity that could lead to a volcanic eruption.

As needed, YVO will be an advisor within the National Incident Management System. The YVO Branch within the Plans Section of the Incident Command will consist of two prescribed groups (Monitoring and Information). The two groups and their subsidiary teams form a scalable system to respond to a variety of scenarios of geologic and volcanic unrest. The YVO response will be led by the YVO Branch Chief (also known as the Scientist-in-Charge) with the assistance of group supervisors and team leaders.

Formal alerts and information statements will be issued by the U.S. Geological Survey (USGS) in conjunction with YVO member agencies and through standard telephone and Internet "calldown" lists. External communications will be coordinated by the public information team leader, in association with any Joint Information Center set up through the Incident Command. Internal communications will be handled through a computerized log system that can be used as an archive for public and non-public documents, and to provide a forum for discussion by observatory personnel and collaborators.

${ }^{1}$ This report was prepared jointly by the attendees of the Yellowstone Volcano Observatory planning meeting. Attendees include Jacob B. Lowenstern, John Bellini, Dan Dzurisin, John Eichelberger, Margaret Mangan, Jill McCarthy, Manuel Nathenson, and Willie Scott of the U.S. Geological Survey; Henry Heasler, Michael Keator, Christine Lehnertz, and Tom Olliff of Yellowstone National Park; Robert B. Smith, Walter Arabasz, Relu Burlacu, Dave Drobeck, Jamie Farrell, and Michael Thorne of the University of Utah; Roy Breckenridge of the Idaho Geological Survey; Edmund Deal, and Michael Stickney of the Montana Bureau of Mines and Geology; Allory Deiss and Ron Surdam of the Wyoming State Geological Survey; and Mike Jackson and Dave Mencin of UNAVCO. Tina Neal and Cynthia Gardner of the U.S. Geological Survey reviewed this report. A revised version of the report (2014) was reviewed by Duane Champion and Tina Neal.
The response plan will be evaluated and updated every three years by the observatory and will be available through the YVO and USGS public websites. The calldown list will be updated at least once per year and placed on the internal log system.

\section{Introduction and Scope}

\section{1a. Purpose of Plan}

Yellowstone National Park (YNP) is centered on a youthful, active volcanic system in the northern Rocky Mountains of Wyoming, Montana, and Idaho (fig. 1). Over the past 2.1 million years, three immense, explosive volcanic eruptions from the Yellowstone system have blanketed parts of the North American continent with ash and debris. Each of these eruptions created sizable calderas: basins formed by collapse of the ground after evacuation of subsurface magma reservoirs. The Yellowstone Caldera, which comprises nearly one-third of the land area in the park, formed 0.64 million years ago, and was followed by dozens of less explosive but extensive lava flows, the last of which occurred 70,000 years ago. Basin and range extension of the western United States has created a series of regional faults that are responsible for large and devastating earthquakes in the Yellowstone region, along the Teton and Hebgen Lake Faults. The most recent was a devastating $M_{\mathrm{s}} 7.5$ earthquake in 1959 that killed 28 people. Yellowstone's famous geothermally heated waters create fabulous hot springs and geysers, but occasionally explode catastrophically to create hydrothermal (steam) explosion craters found throughout the park.

In 2001, the U.S. Geological Survey (USGS), YNP, and the University of Utah (UU) joined to form the Yellowstone Volcano Observatory (YVO). In 2013, the observatory was expanded to include other institutions, including UNAVCO, the three state geological surveys of Montana, Idaho and Wyoming, and the University of Wyoming (fig. 2). YVO provides professional and critical earth-science expertise, operates modern monitoring facilities, processes and interprets seismic and ground deformation signals, and rapidly assesses the significance of geologic processes that may threaten infrastructure, visitors to YNP, and the public beyond its 


\begin{tabular}{|l|}
\hline EXPLANATION \\
caldera boundary \\
state boundary \\
park boundary \\
roads
\end{tabular}

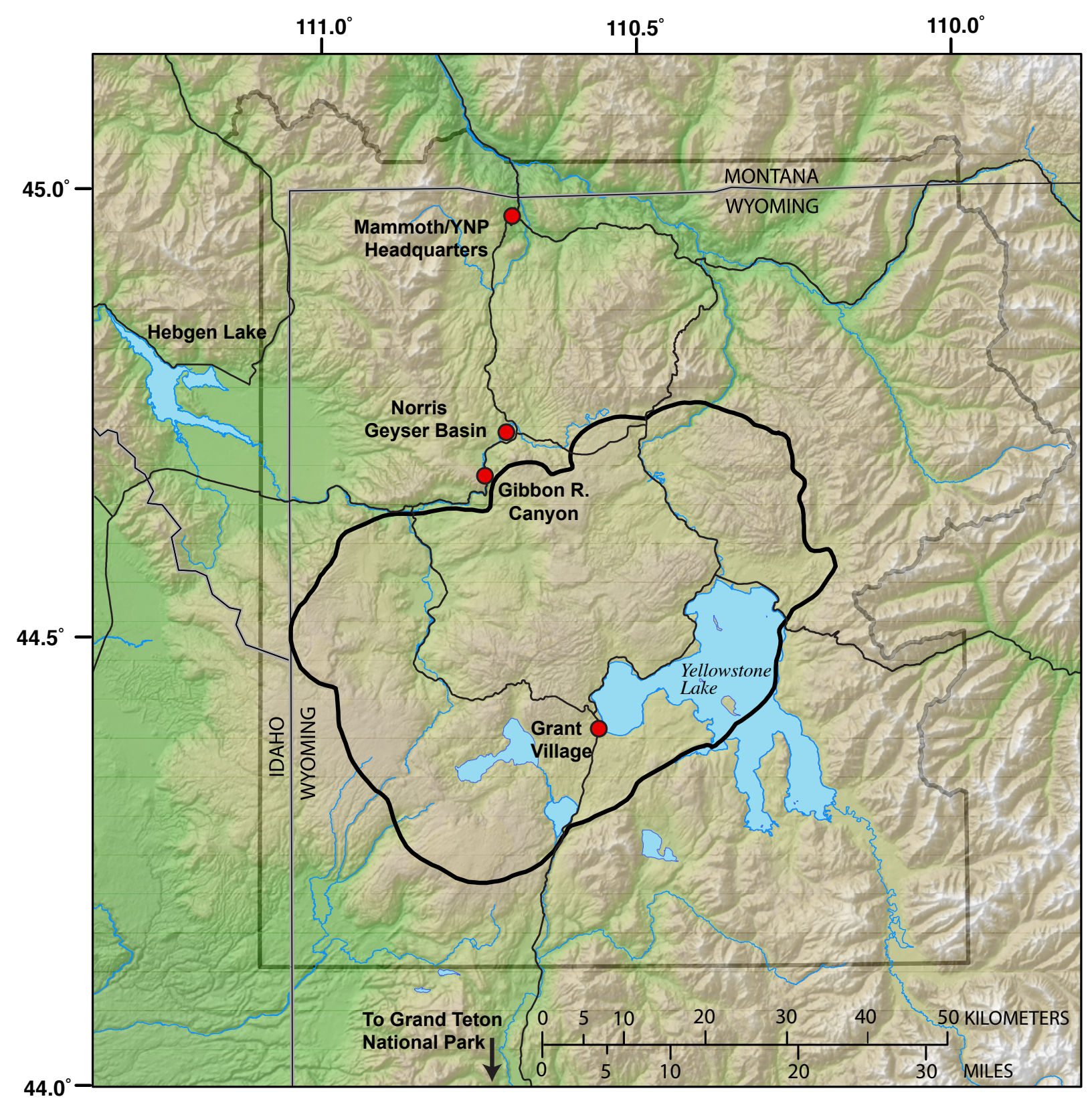

Figure 1. Location map for Yellowstone National Park, including Yellowstone Caldera, roads, state and national park boundaries and place names mentioned in this document. 
borders. YVO provides the necessary information and support to respond rapidly to geologic hazards at Yellowstone and can respond to requests for information from park management, civil authorities, the media, and the public.

Emergency-response readiness is a key responsibility of the USGS Volcano Hazards Program (VHP) stemming from a 1974 congressional mandate that the USGS issue "timely warnings" of potential hazards to responsible emergencymanagement authorities and the public. Both YVO and its parent, the USGS VHP, must maintain capabilities and protocol for the rapid deployment of staff and equipment during periods of seismic, hydrothermal, or volcanic unrest at YNP. This plan provides a basic framework for emergency response by YVO that will be used during periods of geologic unrest at YNP. An initial response plan was published in 2010 (YVO, 2010). This revision incorporates organizational changes to both the observatory and to some of the member institutions. In addition, it reflects recommendations provided by Pierson and others (2013), in their after-action report of a readiness ("table-top") exercise held in 2011 in Salt Lake City, Utah. As with the original response plan, this one is intentionally inwardfocused, identifying the structures and protocols for use within the incident-command, emergency-response structure utilized by YNP. Other documents may concentrate more on plans and communications with other land-management and civil authorities at local, State, and Federal levels.

\section{1b. Organization of YVO}

Although some volcano observatories (including the USGS Hawaiian Volcano Observatory) have facilities and permanent staff, YVO is primarily a partnership, composed of affiliated staff from the eight member agencies (fig. 2). Each agency has an organizational lead that represents its staff to YVO through regularly scheduled meetings and teleconference calls. The

\title{
ORGANIZATION OF YVO
}

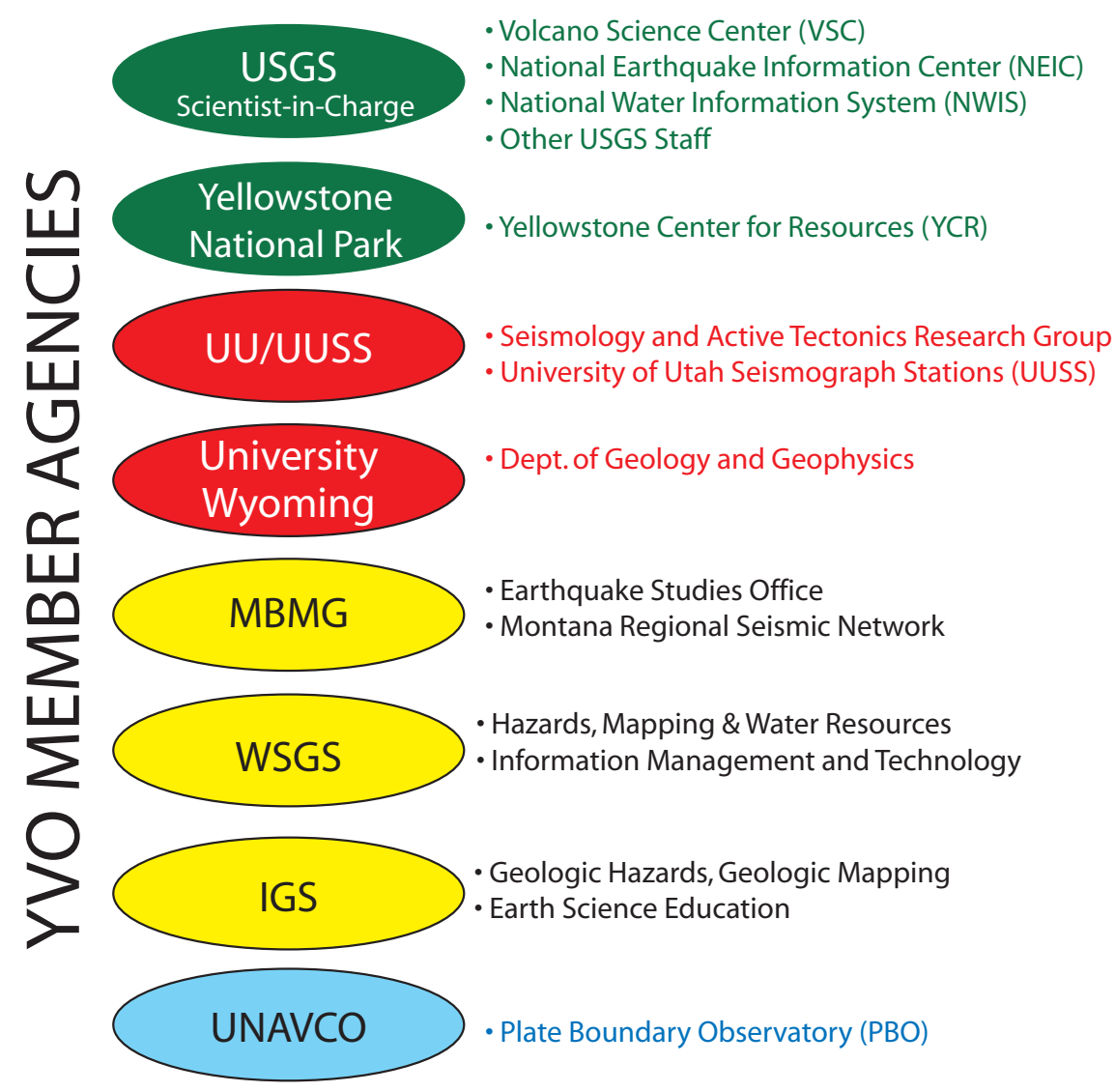

\author{
COLLABORATORS \\ University Researchers \\ IRIS \\ National Science Foundation \\ National Weather Service
}

\section{PRIMARY STAKEHOLDERS}

Figure 2. Organization chart of Yellowstone Volcano Observatory (YVO). The YVO member agencies are the U.S. Geological Survey (USGS), Yellowstone National Park (YNP), University of Utah (UU), University of Wyoming (UW), MBMG (Montana Bureau of Mines and Geology), WSGS (Wyoming State Geological Survey), IGS (Idaho Geological Survey), and UNAVCO. Collaborators include the National Science Foundation, university researchers, the National Weather Service and IRIS (Integrated Research Institutes for Seismology). Stakeholders include the general public, FEMA/DHS (Federal Emergency Management Agency of the Department of Homeland Security), the FAA (Federal Aviation Administration), and state and local emergency managers. 
most recent Memorandum of Understanding (MOU), outlining organizational responsibilities, was signed by all eight members in late 2012 and will remain in effect through 2017. The USGS has the Federal responsibility to provide warnings of volcanic activity, and the USGS grants the Scientist-in-Charge ultimate authority over YVO operations. Key geophysical data are provided by the UU and UNAVCO. YNP is the land manager and is responsible for all emergency response to natural disasters within YNP boundaries. The state geological surveys provide critical hazards information and outreach products to their respective citizens. As much as possible, YVO aids and collaborates with scientists outside the YVO partnership.

\section{1c. Monitoring Systems}

A combination of equipment operated and maintained by many groups inside and outside the YVO partnership is used for real-time monitoring of the Yellowstone volcano. The UU maintains the seismic stations of the Yellowstone Seismic Network and locates earthquakes with the data generated by the network. The Yellowstone Seismic Network is operated by the University of Utah Seismograph Stations (UUSS), which operates its regional seismic network as part of the Advanced National Seismic System (ANSS). Within the ANSS framework, earthquakes throughout the United States larger than about $M 3.0$ are located by the USGS National Earthquake Information Center (NEIC), which operates on a 24-hour-a-day basis, providing backup to the UUSS and other ANSS regional seismic networks. The NEIC operates a small, but modern seismic network in the Teton Range, just south of Yellowstone. The Montana Bureau of Mines and Geology (MBMG) seismic network locates earthquakes in Montana.

Global Positioning System (GPS) receivers are maintained by UNAVCO, a non-profit consortium, funded partly through the National Science Foundation's Plate Boundary Observatory (PBO). Multiple organizations and universities record and process data from the GPS stations and make the data available to the public through websites (for example, http://www. unavco.org http://www.uusatrg.utah.edu/, and the USGS crustal deformation website). The PBO also maintains strainmeters, tiltmeters, and seismometers, all within boreholes drilled in 2007-08 through the National Science Foundation's EarthScope program. Another EarthScope program, USArray, installed state-of-the-art seismic stations within and around Yellowstone as part of a temporary, mobile research array. All were removed in 2010 except for one (near Grant Village) that was left in place as an EarthScope legacy station and given to the UU. Finally, real-time stream flow and meteorological data are collected by the USGS Water Science Centers in Montana, Wyoming, and Idaho, through the National Water Information System (NWIS) with partial funding by YNP. Most of these data streams are available on the internet and can be found at http://volcanoes. usgs.gov/yvo/activity/monitoring/index.php.

During a period of notable geologic unrest, YVO personnel would use these existing data streams and any new data from additional monitoring instrumentation deployed during unrest.
Staff from YVO member agencies and other university and state cooperators would be available to help respond to the needs of the park, press, and public as described in subsequent sections. USGS personnel would include YVO project scientists, VHP staff not normally assigned to work at Yellowstone, seismologists and analysts from the NEIC, and others from other relevant science centers.

\section{Geologic Unrest, Alert Levels, and Information Products}

YVO responds to a variety of geologic events that can signal unrest leading to volcanic eruption. These events include large earthquakes, earthquake swarms, hydrothermal explosions, and increased gas emissions. The nature and frequency of these hazards are discussed in USGS Open-File Report 2007-1071 and in USGS Fact Sheet 2005-3024. With assistance from various partners and collaborators, YVO can also provide rapid response to associated events such as earthquake-induced landslides or floods. Part of any response plan involves organizing and deploying scientific personnel and equipment to investigate current activity and assess possible outcomes and impacts. At the same time, helpful summary information must be provided as soon as possible to land managers, emergency responders, and the public-at-large.

\section{2a. Notification System for Volcanic Activity}

To issue warnings of volcanic unrest and eruptions, YVO utilizes an alert notification system implemented in 2006 by the USGS VHP (http://pubs.usgs.gov/ fs/2006/3139/). This alert system consists of two parallel warning schemes designed for two different types of hazards (airborne ash and gas hazards affecting aviation, and groundbased hazards, see fig. 3). The alerts of airborne hazards to aviation are summarized by four aviation color codes: Green, Yellow, Orange, and Red. The alerts of ground-based hazards use terminology similar to that used by the National Weather Service: Normal, Advisory, Watch, and Warning. Typically, the two four-stage alert levels rise and fall in parallel, yielding Normal/Green, Advisory/Yellow, Watch/ Orange, and Warning/Red, though the system is designed to be flexible so that, for example, alert of an ongoing eruption can remain Warning/Orange if a volcano poses a significant ground hazard but has no significant plume or ash cloud that could endanger aircraft.

The above volcano alert level and aviation color code system has been used by YVO since 2006, and the status of the Yellowstone Caldera has remained Normal/Green during that time. It is important to recognize that large earthquakes, earthquake swarms, or small hydrothermal explosions would not necessarily cause a change in alert level unless those events were thought to be part of an ongoing process that could culminate in a volcanic eruption. 


\section{2b. Event Response}

Such important geologic events as large earthquakes or hydrothermal explosions nevertheless would require action by YVO. For such situations, an event response can be initiated that would include issuance of an information statement summarizing the event and its implications (see next section). An event response includes formal actions taken by YVO, outside of normal monitoring that are intended to characterize anomalous activity, provide assessments of potential outcomes, and inform the public of information gathered. Details of the structure of an event response and how this fits into the National Incident Management System (NIMS) are given in section 4. YVO will respond to earthquakes insofar as to determine their relevance to potential volcanism or hydrothermal explosions, but otherwise will defer to the NEIC regarding seismic summaries and statements of ongoing hazards.

\section{2c. Written Information Products}

Currently, YVO releases a monthly summary update through its website, and through the Volcano Notification Service (http://volcanoes.usgs.gov/vns). This update summarizes seismic, geodetic (ground motion), and unusual hydrothermal activity for the previous month. An information statement is a formal public statement outside of the standard monthly summary updates. Information statements may contain descriptions of changes in monitoring systems, recent non-volcanic activity of note, or other non-urgent information about Yellowstone. If volcanic activity or a large hydrothermal explosion become a likely possibility, YVO will release two additional information products to the aviation community and through the VHP website: the Volcanic Activity Notice (VAN) and the Volcano Observatory Notices for Aviation (VONA). All these products are released electronically

\begin{tabular}{|c|c|c|c|}
\hline & & $\begin{array}{l}\text { Volcano } \\
\text { Alert Levels are intende } \\
\text { and decreasing volcani }\end{array}$ & $\begin{array}{l}\text { Levels Used by USGS Volcano Observatories } \\
\text { form people on the ground about a volcano's status and are issued in conjunction with the Aviation Color Code. Notifications are } \\
\text { ity and are accompanied by text with details (as known) about the nature of the unrest or eruption and about potential or current }\end{array}$ \\
\hline & & Term & Description \\
\hline & & NORMAL & $\begin{array}{l}\text { Volcano is in typical background, noneruptive state } \\
\text { or, after a change from a higher level, } \\
\text { volcanic activity has ceased and volcano has returned to noneruptive background state. }\end{array}$ \\
\hline & & ADVISORY & $\begin{array}{l}\text { Volcano is exhibiting signs of elevated unrest above known background level } \\
\text { or, after a change from a higher level, } \\
\text { volcanic activity has decreased significantly but continues to be closely monitored for possible renewed increase. }\end{array}$ \\
\hline & & WATCH & $\begin{array}{l}\text { Volcano is exhibiting heightened or escalating unrest with increased potential of eruption, timeframe uncertain, } \\
\text { OR } \\
\text { eruption is underway but poses limited hazards. }\end{array}$ \\
\hline & & WARNING & Hazardous eruption is imminent, underway, or suspected. \\
\hline
\end{tabular}

\section{Aviation Color Code Used by USGS Volcano Observatories}

Color codes, which are in accordance with recommended International Civil Aviation Organization (ICAO) procedures, are intended to inform the aviation sector about a volcano's status and are issued in conjunction with an Alert Level. Notifications are issued for both increasing and decreasing volcanic activity and are accompanied by text with details (as known) about the nature of the unrest or eruption, especially in regard to ash-plume information and likely outcomes.

\begin{tabular}{|c|l|}
\hline Color & \multicolumn{1}{c|}{ Description } \\
\hline GREEN & $\begin{array}{l}\text { Volcano is in typical background, noneruptive state } \\
\text { or, after a change from a higher level, } \\
\text { volcanic activity has ceased and volcano has returned to noneruptive background state. }\end{array}$ \\
\hline YELLOW & $\begin{array}{l}\text { Volcano is exhibiting signs of elevated unrest above known background level } \\
\text { or, after a change from a higher level, } \\
\text { volcanic activity has decreased significantly but continues to be closely monitored for possible renewed increase. }\end{array}$ \\
\hline ORANGE & $\begin{array}{l}\text { Volcano is exhibiting heightened or escalating unrest with increased potential of eruption, timeframe uncertain, } \\
\text { OR } \\
\text { eruption is underway with no or minor volcanic-ash emissions [ash-plume height specified, if possible]. }\end{array}$ \\
\hline RED & $\begin{array}{l}\text { Eruption is imminent with significant emission of volcanic ash into the atmosphere likely } \\
\text { OR } \\
\text { eruption is underway or suspected with significant emission of volcanic ash into the atmosphere [ash-plume height specified, if possible]. }\end{array}$ \\
\hline
\end{tabular}

Figure 3. Charts showing the U.S. Geological Survey Volcano Hazards Program system for volcano alert levels. Two parallel scales correspond to ground and aviation hazards. 
through the USGS Hazard Activity Notification System (HANS). They are automatically forwarded to a variety of government agencies, to the YVO and VHP websites, and to partners and collaborating agencies. Currently, the public and media can subscribe to the VNS (Volcano Notification Service) on the VHP website (http://volcanoes.usgs.gov/vns/). A similar service is offered for earthquakes through the EHP (https://sslearthquake.usgs.gov/ens/). Emergency managers and cooperators may also receive these information products automatically as emails or text messages sent at the time of release. To demonstrate the use of an event response and these information products, two plausible scenarios and potential responses by YVO are outlined in Section 7.

\section{YVO and the National Incident Management System}

In the event of a volcanic eruption, large earthquake, or hydrothermal explosion where lives are at risk, infrastructure is threatened, or access needs to be controlled, YNP would activate an Incident Response within the Incident Command System (ICS). The response may be run entirely by park staff or, where desired, as a collaboration of multiple organizations such as nearby counties, states, or federal land management agencies. The response would be structured within the NIMS, a program developed by the Federal Emergency Management Agency of the U.S. Department of Homeland Security. The NIMS approach is defined at http://www.fema.gov/ national-incident-management-system.

The National Incident Management System (NIMS) is a systematic, proactive approach to guide departments and agencies at all levels of government, nongovernmental organizations, and the private sector to work together seamlessly and manage incidents involving all threats and hazards - regardless of cause, size, location, or complexity - in order to reduce loss of life, property and harm to the environment.

...by using NIMS, communities are part of a comprehensive national approach that improves the effectiveness of emergency management and response personnel across the full spectrum of potential threats and hazards (including natural hazards, terrorist activities, and other human-caused disasters) regardless of size or complexity.

During events when human and financial resources need coordination, an ICS can provide infrastructure and transportation (for example, temporary headquarters or helicopter access) to aid YVO in its mission to provide timely assessments to the park and the public. The establishment of an ICS would allow YVO to fit into a larger organization ensuring public safety, clear communications, transportation, and other critical needs. A schematic diagram (fig. 4) illustrates how the ICS may be organized and how YVO would fit into the ICS. All YVO team leaders are strongly encouraged to familiarize themselves with ICS procedures and methodology and, as practical, to take formal training.

\section{Event Response}

\section{4a. Declaring an Event Response}

After consultation with YVO colleagues, including those from YNP, the Scientist-in-Charge may declare a formal event response. In doing so, the Scientist-in-Charge will release an information statement that includes details of the geologic or geophysical activity and, if appropriate, a pronouncement that YVO will initiate increased monitoring during the period of unrest. Not all event responses will result in a change in the alert levels (or release of a VAN or VONA).

\section{4b. Relation of YVO Event Response to Incident Command System}

Declaration of an event response does not in any way obligate YNP to implement an ICS. However, if YNP, or surrounding land managers or communities decide to implement an incident command, YVO would form a branch of the ICS and would act as an advisor on geologic conditions, potential scenarios for future activity, and hazards assessment (fig. 4). It is also possible that the park could stand up an ICS without YVO declaring an official event response, as there are situations where geologic and geophysical activity are unlikely to result in additional hazards (for example, a landslide that blocks road access, or a large earthquake without volcanic consequences).

\section{4c. Internal organization of YVO during a response}

In preparation for an event response or participation in an ICS, YVO will utilize an organizational scheme based on figure 5; the YVO Branch Organization contains teams and groups that are provisionally assigned prior to the event. In ICS terminology, which will be used in subsequent sections of this document, the head of the event response is the YVO Branch Chief (also known as the Scientist-in-Charge). The Branch Chief is assisted by the Deputy Scientist-in-Charge, who also acts as the Scientist-in-Charge when the Branch Chief is unavailable. The event response will be overseen by two functional groups: monitoring and information. The YVO Branch Chief, in consultation with the deputy and team leaders, will determine the assignment of team and group 


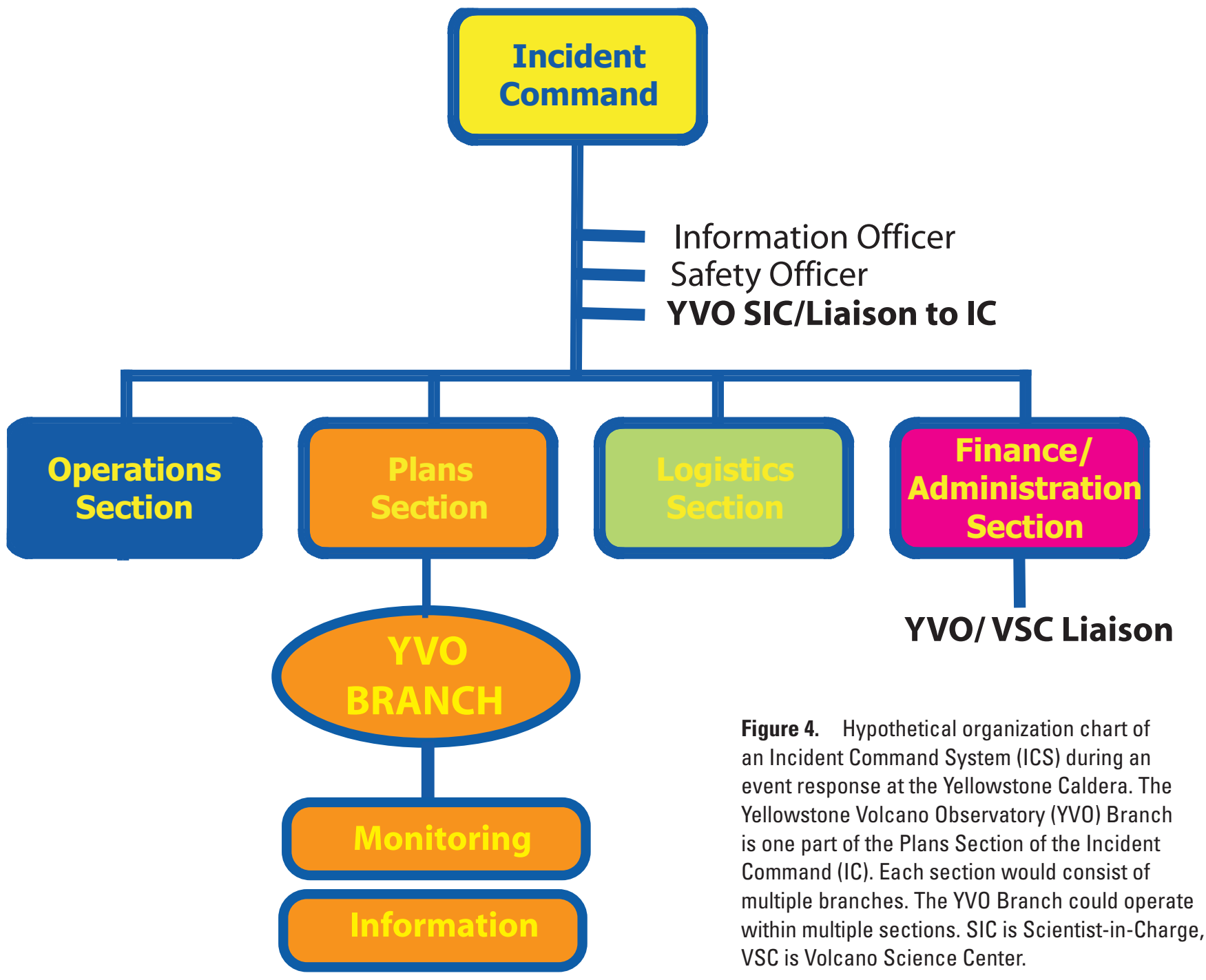

roles. The smallest scale of event response would include a single person in each group. Team members may come from any of the YVO member agencies. Individually, each group and the teams that compose those groups would convene at regular intervals, typically once per day. If appropriate and logistically feasible, all groups and teams could convene together at a single meeting. Because YVO is a distributed partnership with staff in multiple locations, it is expected that meetings would be primarily by teleconference or video conference. Decision making by all team members, regardless of institutional affiliation, would follow this organizational structure, with ultimate authority placed upon the YVO Branch Chief.

Upon raising the volcano alert level and aviation color code beyond Normal/Green, the YVO Branch Chief will assign a duty scientist. The duty scientist assignment will be filled 24 hours a day and will be rotated among the available qualified staff, so that one individual is always responsible for evaluating the latest monitoring data. During an event response when the volcano alert level remains at Normal/ Green, the assignment of staff to the duty scientist is at the discretion of the YVO Branch Chief.

\section{Monitoring Group}

The monitoring group consists of up to four teams (seismology, geodesy, geology [including hydrology and geochemistry], and remote sensing). The supervisor for the monitoring group is the Deputy Scientist-in-Charge. Similarly, for event responses of limited scope, the teams may consist solely of the team leader or may be larger. The team leaders will convene regularly, with a frequency chosen by the group supervisor. When the volcano is at an elevated alert level/color code, each team will grow to be composed of multiple team members as shown in figure 5 and described below. In these instances, at least one team member will be located at YNP or its immediate vicinity. Each team will convene at regular intervals (at least once per day) to characterize ongoing activity, discuss 


\section{Example YVO Branch Organization: 2013 (headed by Branch Chief/ Scientist-in-Charge)}

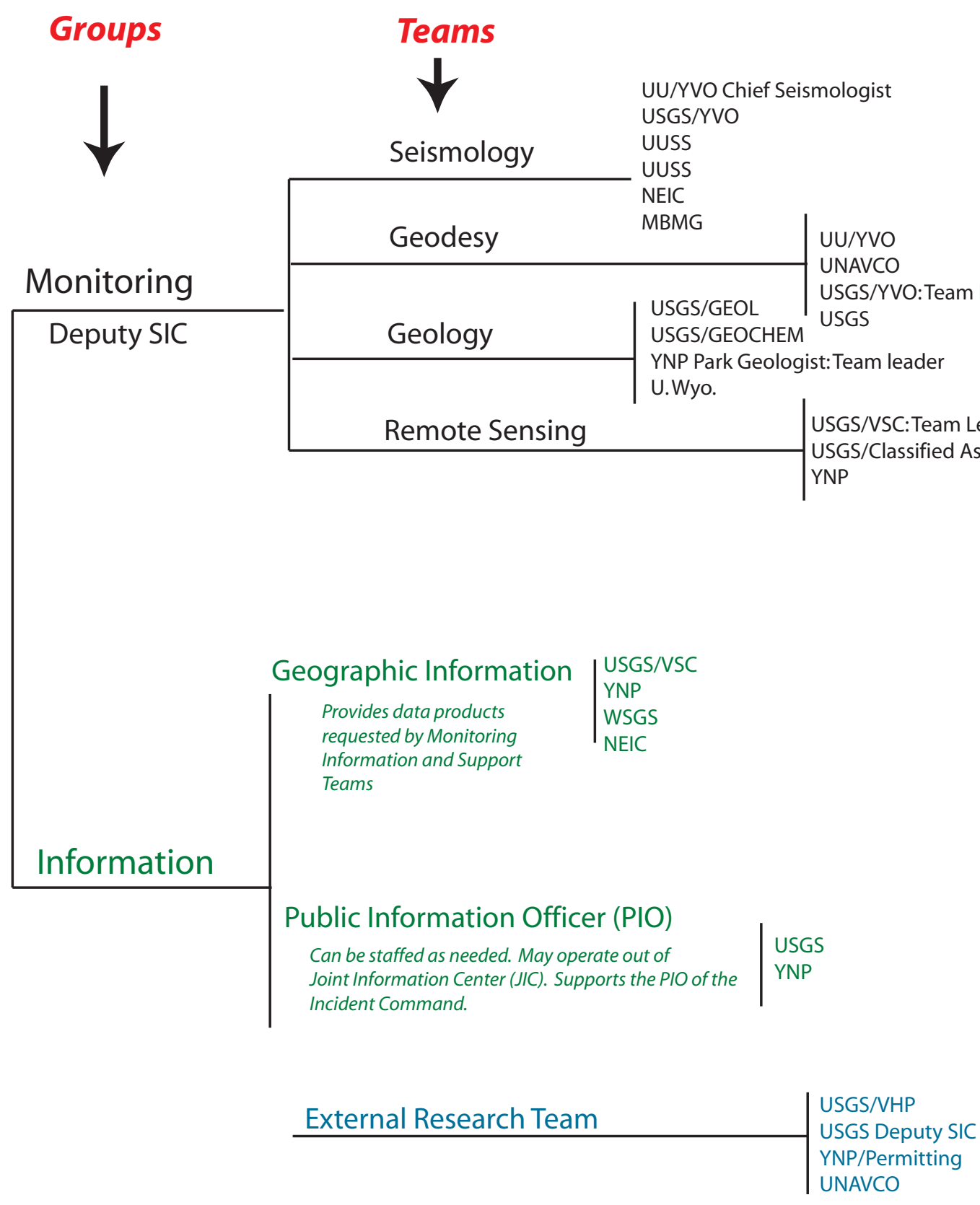

Figure 5. Chart showing Yellowstone Volcano Observatory (YVO) Branch Organization. The YVO Branch consists of two groups divided into various teams. In this diagram, the teams are populated with one possible grouping of people, though other options may be preferred at the time of unrest. The roles of Groups and Teams are explained in the text. The external research team reports directly to the Scientist-In-Charge (SIC). MBMG is Montana Bureau of Mines and Geology, NEIC is National Earthquake Information Center, USGS is U.S. Geological Survey, UU is University of Utah, UUSS is University of Utah Seismograph Stations, U. Wyo. is University of Wyoming, VSC is Volcano Science Center, VHP is Volcano Hazards Program, WSGS is Wyoming State Geological Survey, YNP is Yellowstone National Park, YVO is Yellowstone Volcano Observatory. 
upcoming plans, and provide a summary statement for their team within the monitoring group.

The following section describes the existing standard set of teams that would be used during geologic unrest. Based upon experience at other USGS volcano observatories, these teams would need to expand to meet the demand for field personnel during any extended period of unrest (more than a few weeks). As such, the teams outlined below are minimum organizational units for an event response when a Volcano Advisory or Watch has been issued.

The seismology team consists of the YVO Chief Seismologist and representatives from the Yellowstone Seismic Network, as well as seismologists from several institutions within YVO. The team tracks locations, magnitudes and depths of earthquakes with time, and analyzes waveforms to interpret the source and nature of the earthquake activity. The team is responsible for deploying necessary temporary equipment to increase understanding of the unrest. As needed, the USGS would provide equipment and additional help, either through VHP staff located at other volcano observatories or Earthquake Hazards Program staff, including those at the NEIC. These individuals could be deployed to YNP, or to UUSS facilities in Salt Lake City.

The geodesy team currently will consist of geodetic experts from a variety of YVO member agencies, as needed. This team is responsible for identifying trends in ground deformation that relate to current unrest, using data from continuous GPS stations, borehole strainmeters and tiltmeters, and interferometric synthetic aperture radar (InSAR) observations. The team is responsible for deploying any needed temporary equipment to increase understanding of the unrest and for developing numerical models of the source(s) of deformation.

The geology team is responsible for noting changes in hydrothermal activity, gas discharge, water chemistry, or other geologic factors accompanying unrest. They assist in planning, organizing and staffing fixed-wing aircraft and helicopter surveillance flights. The team is responsible for deploying any needed temporary equipment to increase understanding of the unrest.

The remote sensing team is responsible for identifying any changes in topography, heat discharge, vegetation, or other surface characteristics that can be tracked from air or space. A representative from this team coordinates with the geology team to recommend and deploy any instrumentation that can help the remote sensing team to interpret remotely sensed data. Under some circumstances, the YVO Branch Chief may merge the geology and remote sensing teams under one team leader.

\section{Information Group}

The information group consists of two teams (geographic information and public information) and during small events is supervised by the team leader of the public information team. The information group supervisor is alternatively known as the Public Information Officer (PIO, see fig. 5).
The geographic information team provides visual and cartographic data products and support as requested by the monitoring, information, and support groups. The team assists the Public Information Team in providing contextual materials for distribution to the media and to the public through the YVO website. The public information team is led by an individual from the USGS and may consist of a variety of team members from YVO member and affiliated agencies. The team consists of specialists with technical familiarity sufficient to conduct outreach and education through the YVO website. The team also serves as a resource of scientific information as part of any joint information center (JIC) set up within the ICS. The team is responsible for summarizing current scientific knowledge as "talking points" and conceiving and producing illustrations for use in communicating geologic concepts, hazards, and ongoing activity to the public. The team leader serves as YVO's primary contact with the incident command's PIO, the latter being a position that is likely to be held by a representative from YNP or a local governmental agency.

\section{Support, logistics and external research}

In the previous version of this planning document (Yellowstone Volcano Observatory, 2010), YVO included a separate support group. In this update, we have eliminated this group. Logistics within the ICS are coordinated outside of YVO and can assist with setting up a field office, lodging, helicopter support, and so forth. Staffing and budgeting within the USGS or as part of a USGS cooperative grant are outside the purview of YVO itself, and need not constitute a separate group. Coordination with the ICS will occur through a liaison from YVO or the Volcano Science Center (VSC) that will interface with the Finance/Administration section (fig. 4). In addition, the Deputy Scientist-in-Charge will continue to work with VSC management to incorporate USGS staff into the event response or to identify personnel from YVO member agencies.

The external research team will remain as an advisory group to the Branch Chief and consists of 3 or 4 people including a team leader from the monitoring group. The team will act as a liaison with scientists from outside YVO, including other governmental and academic institutions. Scientists interested in assisting with the event response or conducting independent or collaborative related research will send communications to the external research team for vetting of research proposals, assistance with logistics, and coordination of sample and data distribution. The team will include scientists from the VHP, academia, UNAVCO, and a member of the YNP research permitting office, all who are not intimately involved with the event response and can be impartial coordinators for diverse groups seeking to undertake fieldwork, deploy instrumentation, acquire data, or collect samples as part of the response. The team leader from the monitoring group will coordinate with the rest of the monitoring teams to ensure 
that the external research complements ongoing monitoring programs and does not negatively impact logistics.

\section{4d. Calldown and Related Communications Lists}

Upon declaring an event response or announcing a change in the volcano alert level or aviation color code, YVO will institute a formal calldown whereby staff will place telephone calls to notify colleagues and cooperators of the current situation. Figure 6 is an example of the calldown scheme. A version of the YVO calldown list will be populated with phone numbers, web, and email addresses, and placed on the YVO internal log system for retrieval by YVO staff and cooperators. In addition, most of the individuals on this list will also be sent an automatic email or text message to their computer and (or) phone at the time of the information statement and (or) alert-level change and accompanying information products (VAN/VONA). As such, the telephone call may be redundant, but allows back-andforth discussion between YVO staff and key distributors of hazards information. In the current plan, YNP or the ICS staff above the YVO Branch will contact state and local emergency managers, as well as relevant personnel within YNP. The UU will be responsible for contacting regional seismic networks. The YVO Branch Chief or a designee will alert the VHP Coordinator and the VSC Director, who in turn notify USGS regional and national program contacts and the Department of the Interior Watch Office. The VHP Coordinator will also interface with the Hazard Response Executive Committee that oversees USGS responses to hazardous events.

The YVO calldown list will be reevaluated at least once per year and will be maintained by the YVO PIO and stored on the internal log system.

\section{4e. Information Releases}

As of September 2014, YVO issues a monthly update on the status of the Yellowstone volcano on or around the first day of each month. The update synthesizes the monitoring information and expert opinion solicited from YVO cooperators and collaborators. After a notable earthquake, earthquake swarm, hydrothermal explosion or other geologic event, the observatory may choose to release an information statement that provides details on the event and possible outcomes. During an event response, frequency of the updates is at the discretion of the YVO Branch Chief. If warranted, the YVO Branch Chief may opt to change the alert level and aviation color code. After an upgrade in alert level, YVO will release daily updates.

Currently, the UUSS policy is to issue a press release after any earthquake greater than $M 3.5$ within the UUSS reporting area of the Yellowstone region. They typically do the same after the onset of any significant earthquake swarm, especially those that attract public interest or include felt events. YVO then re-issues the press release as an information statement. YVO may include additional content in the information statement as it relates to potential volcanism. However, YVO defers to the NEIC and any regional earthquake network (for example, UUSS) for information specifically related to earthquakes.

As discussed above, while alert levels are elevated YVO will release daily updates. During such times, separate press releases by member agencies should be closely coordinated with the public information team (or the Joint Information Center organized through the ICS structure). In contrast, during quiet periods, Yellowstone-related press releases by any of the YVO member agencies can be vetted through the other partners, and such communication is encouraged, but not mandated.

\section{Alert Notification Scheme and Decision Criteria}

The VHP criterion for a volcano advisory/aviation color code Yellow includes the following: "Volcano is exhibiting signs of elevated unrest above known background level." Assessing what constitutes elevated unrest is somewhat subjective and requires consideration of both the type and level of activity, as well as the historic behavior of the volcanic and hydrothermal system. For example, during an earthquake swarm, activity may be above known background levels, but because swarms are characteristic of this hydrothermal region, is not necessarily a precursor to an eruption. This is in contrast to many stratovolcanoes, where earthquake swarms or ground deformation are almost always a direct result of magma ascent into the upper crust (a shallow intrusion). At Yellowstone, however, earthquake swarms and caldera-wide ground deformation are relatively common events that can reflect regional tectonism, hydrothermal pressurization and deep magma intrusion that appear to have occurred for thousands of years without ever leading to a volcanic eruption. Similar activity is noted at other large calderas around the world.

The following five guidelines outlined below will inform YVO decision making during future episodes of geologic activity.

1. YVO may choose to initiate an event response for a large earthquake, an intense earthquake swarm, an episode of rapid ground displacement, a significant hydrothermal explosion that generates a large crater (tens to hundreds of meters in diameter), or a pronounced increase in heat or gas discharge.

2. An alert level change from Normal to Advisory (with accompanying change of aviation color code from Green to Yellow) may be declared when monitoring parameters exceed known thresholds previously observed at Yellowstone. One example is an intense earthquake swarm ( $>500$ earthquakes, some with $M>4.5$ ) that is accompanied by rapid 


\section{YVO Provisional Calldown List}

\section{Used when changing volcano alert level or declaring event response}
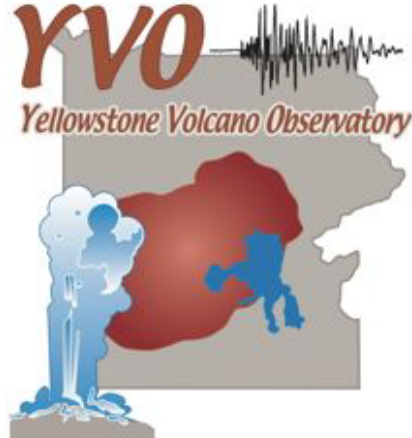

O YVO Scientist-in-Charge calls: Associate Director Natural Hazards DOI 24/7 Watch Office

Relevant USGS Regional Directors)

Volcano Science Center Director

USGS Office of Communications

Wyoming, Montana and Idaho State Geologists

Relevant State Government Offices (Governor, Homeland Security) NOTE: redundant lines of communication through the ICS would provide information to these offices.
O YVO Deputy

Scientist-in-Charge calls:

(Alert level change only)
NWS Meteorologic Watch Office, Kansas City, MO FAA Regional Office Salt Lake City, UT NWS Weather Forecast Office, Riverton, WY NOAA Washington VAAC, Washington, DC FEMA Region VIII contact, Denver, CO

Seismology Team Chief calls (only if they are not already in YVO teams):

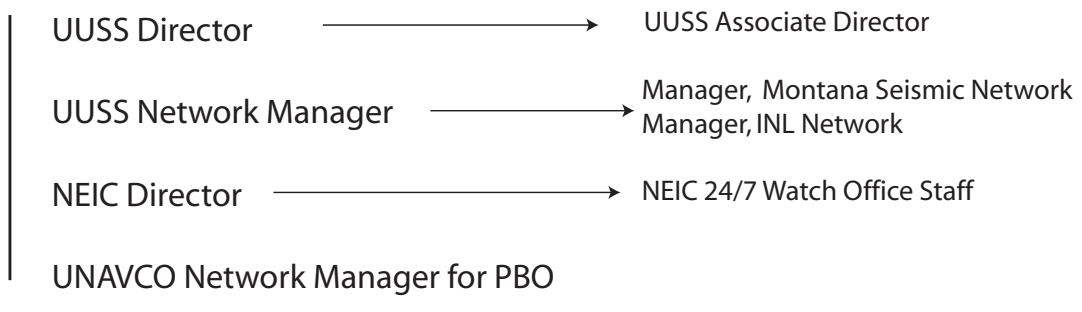

O YNP Chief, Yellowstone Center for Resources calls:

YNP Superintendent

YNP Deputy Superintendent

YNP Chief Ranger

Communications Center

Affected local communities

\section{Alerts also released through the VNS: volcanoes.usgs.gov/vns/ \\ and YVO website activity page (http://volcanoes.usgs.gov/activity/status.php\#yvo)}

Figure 6. Simplified calldown list for Yellowstone Volcano Observatory. Actual calldown list may differ from this example. DOI is Department of Interior, FAA is Federal Aviation Administration, FEMA is Federal Emergency Management Agency, ICS is Incident Command System, NEIC is National Earthquake Information Center, NOAA is National Oceanic and Atmospheric Administration, NWS is National Weather Service, USGS is U.S. Geological Survey, UUSS is University of Utah Seismograph Stations, VAAC is Volcanic Ash Aviation Center, VNS is Volcano Notification Service, YNP is Yellowstone National Park, YVO is Yellowstone Volcano Observatory. 
ground displacement (such as $>5 \mathrm{~cm}$ [2 inches] over 30 days), or a significant hydrothermal explosion. It is unlikely that a Volcano Advisory would be called for a single large earthquake and its sequence of aftershocks unless it was accompanied by considerable pre-earthquake ground displacement or hydrothermal explosions. It is possible that lesser activity could trigger the announcement of a Volcano Advisory. It is also possible that in some situations YVO would choose not to issue a Volcano Advisory, unless all three criteria (an intense earthquake swarm, rapid ground displacement, and a significant hydrothermal explosion) were met. Although the Yellowstone hydrothermal system normally releases abundant carbon dioxide and hydrogen sulfide, it does not normally release high-temperature sulfur dioxide; therefore, any measurable flux of sulfur dioxide (for example, tens to hundreds of tons per day) would merit serious consideration of the issuance of a Volcano Advisory.

3. A change in alert level and aviation color code from Normal/Green to Advisory/Yellow will always trigger a formal event response by YVO.

4. Changes in alert levels and color codes or declaration of an event response are the responsibility of the YVO Branch Chief, who will normally consult closely with the other organization leads and team leaders before making any such decisions.

5. Change from a higher alert level and color code (Advisory or Watch) to a lower alert level will be at the discretion of the YVO Branch Chief, in association with the team leaders and organization leads. The criteria for such a decision are likely to vary widely, depending on the nature of the event.

\section{Scientific Oversight and Information Sharing}

\section{6a. Advisory Panel}

The USGS VHP is currently exploring the development of an oversight committee to provide guidance to all USGS volcano observatories. The panel would be a standing committee focused on maximizing the ability of U.S. volcano observatories to monitor and mitigate volcanic hazards. Such a committee would provide assistance to YVO by undertaking periodic audits of observatory practices, and by serving as additional liaisons to the media for background information during volcano crises.

\section{6b. YVO Log System}

YVO maintains a secured weblog system that provides a forum for discussion of monitoring data. This passwordprotected system shall be used continually, during periods of quiescence and unrest, to provide a searchable archived system of plots, observations, and discourse related to geologic activity at Yellowstone. Such systems have proven critical to information sharing at the Hawaiian, Cascades, and Alaska Volcano Observatories. Log systems ensure that everyone works with the same set of information and that ideas can be shared, discussed, and vetted in an organized manner. The log contains a record of phenomena, ideas, and decision making in the aftermath of events, that can be used by observatory staff to evaluate operational protocols. Unauthorized use of posted data or ideas is unacceptable and could result in exclusion from observatory projects and opportunities.

YVO practice is to make all reliable real-time data available to the public through Internet-based archives (these currently include seismic, GPS, strain, tilt, and hydrologic data). The log system does not contain raw data. Its purpose is to enable discussion among YVO partners. All staff from YVO member agencies with a role in YVO response are strongly encouraged to use the log system and be familiar with its organization (Pierson and others, 2013).

\section{Scenarios of Unrest and Initiation of Event Response}

Two plausible scenarios demonstrate how the YVO response plan might be used as a basis for an event response.

7a. Scenario 1: Day 1: During a 6-hour period on a July afternoon, four $M$ 5-6 earthquakes occur near Gibbon River Canyon (hundreds of smaller events occur over the next three days). Landslides have blocked the roads in Gibbon River Canyon and between Mammoth and Norris Geyser Basin, effectively closing off access to Norris and Mammoth from the southwest.

Coincident with the beginning of earthquake activity, the Norris strain and tilt meters show large signals indicating significant local deformation. Though two continuous GPS receivers (set at minute solutions) are deployed nearby, the data are not telemetered.

Day 2: Hydrothermal explosions are detected in the Norris Back Basin, leading to closure of the entire Norris Geyser Basin. The largest resulting crater is 20 meters in diameter; 15 additional hydrothermal 
explosions are detected with the Norris seismometer and strain meter.

On Day 1, YNP initiates an ICS to help manage transportation around the affected area, restore infrastructure, and assist park visitors. YVO initiates an event response and is designated as a branch within the "Plans" section of the ICS structure. At the same time, a Volcano Advisory and aviation color code Yellow are declared by the YVO Branch Chief along with a summary of observations and current prospects for future activity. A VAN/VONA is issued by the YVO Branch Chief and a calldown is completed. The event response requires formation of 3 teams ( $\sim 13$ people) within the monitoring group (seismology, geodesy and geology/remote sensing). The information group consists of three individuals (two in the geographic information team), and is supervised by the public information team leader. Team members of the monitoring group plan for deployment of additional equipment to detect local deformation and assist in the identification of seismic sources that could indicate migrating magma. The YVO Branch Chief works with the public information team leader to create information products. These are for use during a press conference on Day 2, set up through the ICS. A duty scientist position is created, which rotates among the team leaders for Day 2 and Day 3.

On Day 3, representatives of the YVO advisory panel are contacted by the YVO Branch Chief and a conference call is set up between the advisory panel, the YVO team leaders, and the Branch Chief. Assuming that unrest did not increase, this basic organizational structure would be used for response to the initial unrest, and would remain in place for as long as desired by the Branch Chief and the ICS.

7b. Scenario 2: Day 1: Forty $(M>2.0)$ earthquakes are recorded over a 10-hour period on a winter day at Yellowstone Lake. Several of the earthquakes are felt by park staff, but no damage is recorded. No deformation or hydrothermal changes are noted.

Day 2: The swarm continues and residents express concern about their safety. $200 M>2.0$ earthquakes are now recorded.

On Day 3, YNP initiates an ICS to help plan possible options for moving staff out of the Yellowstone Lake area to alterative locations in the park. The YVO Branch Chief releases an information statement and begins an event response. The alert level and avaiation color code remain at Normal/Green. The monitoring group consists of the Chief Seismologist and the Park Geologist. The information group consists of a single person from the USGS. At the discretion of the YVO Branch Chief, a daily information statement is provided through the YVO website and the VNS until the swarm ceases. Due to the relatively low level of activity, YVO decides not to deploy temporary equipment unless geologic activity increases. The incident command managers have a daily teleconference to re-assess the situation, including whichever YVO-affiliated staff are needed. No YNP staff are moved from the area. The earthquake swarm eventually ceases after six days, and the ICS is demobilized at that time.

\section{Summary and Protocols for Updating this Plan}

This plan summarizes protocols and tools to be used by the Yellowstone Volcano Observatory during episodes of unusual geologic unrest at the Yellowstone Caldera.

- The YVO Branch Chief will call for an event response, and will enter into an ICS led by YNP or another land management agency if appropriate. The YVO Branch within the Plans Section of the Incident Command will consist of prescribed groups (Monitoring and Information) and their associated teams.

- Information will be provided externally through the USGS Hazard Activity Notification System (HANS), the YVO and USGS VHP websites, and a calldown list. Internal communications will be organized through group and team meetings and through the YVO log system.

- This plan will be modified every three years to account for changes in staff, organizational structures, and protocols. The current version of this plan will be available through the official USGS publications website for viewing by the general public. Similarly, the calldown list and group and team members list will be kept up-to-date on the internal secured log system and will be updated yearly.

\section{For more information:}

Brantley, S.R., Lowenstern, J.B., Christiansen, R.L., Smith, R.B., Heasler, Henry, Waite, Greg, and Wicks, Charles, 2004, Tracking changes in Yellowstone's restless volcanic system: U.S. Geological Survey Fact Sheet 100-03, 4 p., available at http://pubs.usgs.gov/fs/fs100-03/.

Christiansen, R.L., Lowenstern, J.B., Smith, R.B., Heasler, Henry, Morgan, L.A., Nathenson, Manuel, Mastin, L.G., Muffler, L.J.P., and Robinson, J.E., 2007, Preliminary assessment of volcanic and hydrothermal hazards in Yellowstone National Park and vicinity: U.S. Geological Survey Open-File Report 2007-1071, 94 p., available at http://pubs. usgs.gov/of/2007/1071/. 
Department of Homeland Security, 2008, National Incident Management System: Federal Emergency Management Agency, 155 p., available at http://www.fema.gov/pdf/emergency/nims/NIMS_core.pdf.

Gardner, C.A., and Guffanti, M.C., 2006, U.S. Geological Survey's alert-notification system for volcanic activity: U.S. Geological Survey Fact Sheet 2006-3139, 4 p., available at http://pubs.usgs.gov/fs/2006/3139/.

Lowenstern, J.B., Christiansen, R.L., Smith, R.B., Morgan, L.A., Heasler, Henry, 2005, Steam explosions, earthquakes, and volcanic eruptions - what's in Yellowstone's future?:

U.S. Geological Survey Fact Sheet 2005-3024, 6 p., available at http://pubs.usgs.gov/fs/2005/3024/.

Pierson, T.C., Driedger, C.L., and Tilling, R.I., 2013, Volcano crisis response at Yellowstone Volcanic Complex - after action report for exercise held at Salt Lake City, Utah, November 15, 2011: U.S. Geological Survey Open-File Report 2013-1018, 31 p. available at http://pubs.usgs.gov/ of/2013/1018/.

Yellowstone Volcano Observatory, 2006, Volcano and earthquake monitoring plan for the Yellowstone Volcano Observatory, 2006-2015: U.S. Geological Survey Scientific Investigations Report 2006-5276, 17 p., available at http:// pubs.usgs.gov/sir/2006/5276/.

Yellowstone Volcano Observatory, 2010, Protocols for geologic hazards response by the Yellowstone Volcano Observatory: U.S. Geological Survey Circular, 1351, 18 p.

\section{Websites with Monitoring Data:}

YVO Monitoring Webpage

http:/volcanoes.usgs.gov/yvo/activity/monitoring/index.php

UUSS Recent Earthquakes at Yellowstone National Park

http://www.seis.utah.edu/req2webdir/recenteqs/Maps/

Yellowstone.html

UUSS Seismic Waveform Images (Webicorders)

http://quake.utah.edu/helicorder/yell_webi.htm

UU GPS Data
http://www.uusatrg.utah.edu/ts_ysrp.html

PBO GPS Data

http://www.unavco.org/data/gps-gnss/real-time/real-time.html

PBO Strain Data

http://www.unavco.org/data/strain-seismic/bsm-data/bsm-data. html

YVO Hydrologic Monitoring with Links to NWIS http://volcanoes.usgs.gov/volcanoes/yellowstone/yellowstone monitoring_46.html

\section{To reach YVO:}

email:yvowebteam@usgs.gov To sign up for YVO notifications http://volcanoes.usgs.gov/vns/ 


\section{Glossary of Terminology and Acronyms}

ANSS Advanced National Seismic System: The USGS-sponsored system for providing uniform information products for seismic activity including, locations, magnitudes, effects on buildings, and so forth. Includes the NEIC, the backbone network of USGS seismic stations, and 15 regional seismic networks operated by partner agencies.

Deputy Scientist-in-Charge A deputy Scientist-in-Charge is assigned to assist with communications, calldowns, and other responsibilities. The position serves as the monitoring group leader.

Duty Scientist Rotating position among the team leaders and Scientist-in-Charge. The duty scientist is responsible for continuous, 24-hour-a-day evaluation of monitoring data and communication of important findings to the observatory staff and leadership. The duty scientist position will be utilized whenever the volcano is at an alert level above Normal/Green.

Event Response An official action taken by the observatory to react to an increase in geologic activity.

FAA Federal Aviation Administration

FEMA/DHS Federal Emergency Management Agency of the Department of Homeland Security

GPS Global Positioning System: A satellite-based system for location and navigation. It is used in geoscience (and by YVO) to monitor displacement of benchmarks and other monuments as a means of tracking tectonic and volcanic deformation.

HANS Hazards Activity Notification System: A computer interface used by USGS volcano observatories for issuing volcano alerts, information statements, and other advisories.

ICS Incident Command System: A set of personnel, policies, procedures, facilities, and equipment, integrated into a common organizational structure designed to improve emergency response of all types and complexities.

IGS Idaho Geological Survey

InSAR Interferometric synthetic aperture radar

IRIS Integrated Research Institutes for Seismology

JIC Joint Information Center

MBMG Montana Bureau of Mines and Geology

MOU Memorandum of Understanding

NEIC National Earthquake Information Center: A Denver-based group within USGS responsible for overall monitoring of earthquakes in the United States. Maintains a 24-hour-a-day Watch Office and a "backbone" network of seismic stations that complements regional networks such as UUSS.

NIMS National Incident Management System

NWIS National Water Information System

PBO Plate Boundary Observatory: One of the components of Earthscope, a research facility to explore the structure and evolution of the North American Continent. Earthscope is funded by the National Science Foundation. PBO focuses primarily on ground deformation as measured by GPS, and strain and tilt meters.

PIO Public Information Officer

Scientist-in-Charge The Observatory lead from the USGS, with ultimate authority over Observatory operations. In an ICS, the Scientist-in-Charge serves as the YVO Branch Chief.

UNAVCO Non-profit consortium that, in part, assists the National Science Foundation with installation and operation of PBO instrumentation.

USGS U.S. Geological Survey

UU University of Utah

UUSS University of Utah Seismograph Stations: A research, educational and public-service entity that serves as an ANSS regional network and serves populations in Utah, eastern Idaho, and western Wyoming. UUSS is responsible for location of earthquakes at Yellowstone as part of the MOU for the YVO.

University of Utah Seismology and Active Tectonics Research Group Researchers, faculty and students focused on interpreting and modeling the Yellowstone region seismic and ground deformation data acquired by the UU and others. Research projects include the Yellowstone hotspot, seismicity, magmatism, heatflow, and ground deformation.

UW University of Wyoming

VAAC Volcanic Ash Aviation Center

VAN Volcanic Activity Notice

VHP Volcano Hazards Program: USGS program that funds the USGS Volcano Observatories and the VSC, which administers most USGS employees involved in volcano-related projects.

VNS Volcano Notification Service: a free service that sends notification emails about volcanic activity at U.S. monitored volcanoes.

VONA Volcano Observatory Notices for Aviation

VSC Volcano Science Center: The organizational unit within which most USGS volcano scientists reside. Staff are located primarily at the Alaska, Cascades, and Hawaiian Volcano Observatories, and in Menlo Park, California. Led by the VSC director. 
WSGS Wyoming State Geological Survey

YNP Yellowstone National Park

YVO Yellowstone Volcano Observatory

YVO Branch The organizational unit occupied by YVO within the Plans Section of the ICS; led by the YVO Branch Chief (Scientist-in-Charge).

YVO Collaborating Organizations Informal cooperators such as university researchers, the Idaho National Lab Seismic Monitoring Program, the Integrated Research Institutes of Seismology, the National Weather Service, and the National Science Foundation/Earthscope. Some of these organizations have a MOU and a cooperating agreement with one or more YVO member agencies.

YVO Member Agencies These include the USGS, YNP, UU, UW, WSGS, IGS, MBMG and UNAVCO. All are signatories to the YVO MOU, most recently signed in 2012. 
Menlo Park Publishing Service Center, California

Manuscript approved for publication September 16, 2014

Edited by Theresa Iki and Regan Austin

Design and layout by Stephen L. Scott and Cory Hurd 
훙

음

응

กิ

홍

http://dx.doi.org/10.3133/cir1351

ISSN 1067-084X (print)

ISSN 2330-5703 (online) 